\title{
Inserción de los profesionales sanmarquinos en el mercado laboral global, 2010-2015 Un estudio de casos hacia una visión sociohistórica prospectiva
}

Recibido: 20/09/2016

Aprobado: 24/10/2016
Jaime Ríos Burga'

Universidad Nacional Mayor de San Marcos

$<$ jaimecultura1@gmail.com >

\begin{abstract}
RESUMEN
La inserción laboral hoy en el mercado laboral global de los profesionales sanmarquinos muestra una estructuración todavía predominantemente masculina aunque con la tendencia en la creciente incorporación femenina, en una situación estructural de una reducida obtención de los grados y títulos de licenciados, maestristas y doctorandos. Como también la importancia para el acceso laboral de la experiencia y la formación aplicada en las carreras profesionales. Para lo cual los egresados ante la falta de una institucionalidad y política de incorporación laboral crean sus propias estrategias acorde a las habilidades y capacidades técnicas, además del título profesional obtenido y la experiencia laboral acumulada. Situación que determina su nivel de ingreso y expectativas profesionales, en un marco creciente de flexibilización y privatización en el mercado laboral global.
\end{abstract}

Palabras clave: Inserción laboral, profesionales, mercado laboral, Perú y Universidad Nacional Mayor de San Marcos.

\section{Insertion of San Marcos professionals in the global labor market, 2010-2015. A case study to a prospective socio-historical vision}

\begin{abstract}
The labor market today in the global labor market professionals San Marcos professionals show a still predominantly male but the trend structuring in the growing female incorporation into a structural situation of reduced obtaining degrees and diplomas of graduates, and doctoral students, mastership. As the importance for job access and training experience applied in professional careers. For which graduates in the absence of an institutional and policy labor incorporation create their own strategies in line with the skills and technical capabilities, in addition to the professional title obtained and the accumulated work experience. Situation that determines your level of income and professional expectations, increasing flexibility and privatization in the global labor market
\end{abstract}

KEYworDs: Job placement, professional, labor market, Peru and Mayor de San Marcos National University

1 La presente investigación fue producto de un trabajo en equipo con mis alumnos de sociología Luis Romero y Arturo Huaytalla. 


\section{Ubicación de la problemática}

L os antecedentes de los estudios desde una perspectiva teórica empiezan a desarrollarse a pesar de su importancia estratégica para la universidad y el país. Como destacan algunas investigaciones el acceso al mercado laboral es diferenciado y desigual, dependen mucho de las exigencias de los empleadores y una formación profesional pertinente en sí misma.

Un vistazo general a los egresados de la licenciatura permite entrever que, en consonancia con lo que acontece a nivel de América Latina, las primeras experiencias de búsqueda de trabajo son azarosas, redundando en una considerable proporción de egresados sin trabajo, de los cuales, prácticamente gran parte sobre todo de la universidad pública consideran mermadas sus posibilidades de obtener un trabajo debido a la falta del título profesional.

En este contexto nos planteamos la siguiente pregunta de investigación general: ¿Cuál es la situación de la inserción laboral de los profesionales sanmarquinos en el mercado laboral? Como específicas: a) ¿Cómo se insertan los profesionales sanmarquinos en el mercado laboral?; b) ¿Cuál es la situación laboral en la que se encuentran actualmente?; c) ¿Cuáles son sus satisfacciones y expectativas profesionales en el mercado laboral?

Partimos de la siguiente hipótesis de trabajo: La inserción de los profesionales sanmarquinos en el mercado laboral global se da de una manera desigual y diferenciada según las carreras profesionales, debido a factores formativos de demanda del mercado global e institucional, como de satisfacción de expectativas personales y de género en un contexto cada vez más dinámico y cambiante.

Nos encaminamos en general a comprender y explicar los procesos y situaciones de la inserción laboral de los profesionales sanmarquinos en el mercado laboral; y, en específico: a) Conocer cómo se insertan los profesionales sanmarquinos en el mercado laboral, b) Conocer la situación laboral en la que se encuentran actualmente los profesionales sanmarquinos, c) Conocer sus satisfacciones y expectativas profesionales en el mercado laboral.

La situación laboral de los profesionales sanmarquinos se ubica hoy en el marco de las nuevas demandas de la sociedad del conocimiento, el impacto del modelo de apertura que trae hoy la globalización y la especificidad del mercado laboral profesional nacio- nal. Factores entre otros que procesan una restructuración de los modelos, las áreas y las líneas y las políticas en un marco sistémico institucional cada vez más diferenciado entre su incorporación a la nueva dinámica de acumulación y realización del capital como de su efectos de flexibilización, inclusión, exclusión y precarización laboral. Proceso que prospectivamente tenemos que afrontar con políticas institucionales que conduzcan hoy a una nueva relación caracterizada por el vínculo directo Mercado-inserción laboral. La inserción laboral encuentran aquí nuevos modelos, áreas, líneas y políticas en un marco cada vez más globalizado y diferenciado.

Históricamente ubicamos tres modelos centrales que marcan la inserción profesional: a) Primario exportador; b) Industrialización por sustitución de importaciones; c) modelo de apertura neoliberal. La CEPAL plantea que en los ańos noventa y mediados del año 2000 la inserción laboral ubicaba los siguientes desafíos con relación a la empleabilidad: a. Una buena educación y formación para el trabajo son elementos clave en el desarrollo del capital humano y la empleabilidad de los jóvenes. b. Que la distribución del capital social se convierte en un factor central para superar las inequidades socioeducativas y de inserción en el mundo laboral. c. cada vez más para las empresas los valores y las aptitudes como capital cultural se convierte en un factor a tomar en consideración en la incorporación al mundo laboral.

En relación a la equidad de género destaca: a. la situación de la desigualdad estructural de la condición de género plantea un cambio cultural con relación al patrón tradicional masculino. El espíritu "emprendedor" del mercado neoliberal plantea una transformación productiva con un espíritu innovador y de permanente conocimiento de la información y comunicación organizacional ante la flexibilización global de los mercados donde la creación de empleo si bien en algunas empresas se afirma que contratan a jóvenes profesionales con una buena formación, aunque no tengan experiencia, de hecho para la inserción laboral de los jóvenes se suele plantear exigencias adicionales (de experiencia, conexiones personales, manejo de pautas culturales, esfuerzo individual y otras).

En las últimas décadas destaca un aumento en la participación laboral femenina en el Perú. Para la teoría de la segregación laboral es caso chileno por ejemplo muestra que: a. Los procesos de reestructuración, específicamente de racionalización productiva implemen- 
tados en la región en las últimas décadas van transformando la participación en la inserción laboral urbana en nuestros países, nuevamente al género como uno de los criterios de ordenamiento de la división del trabajo social. b. La mayor incidencia de esta transformación se encuentra en los sectores tanto productivos como de las organizaciones educacionales y de salud, en especial aquellas correspondientes al sector privado de la economía. c. Esta tendencia pareciera, a pesar del impacto de la crisis presente en la región, no revertirse sino por el contrario mantenerse en el tiempo. d. Pero la segregación laboral según género en la región y el Perú sigue estando presente tanto en términos horizontales como verticales, contribuyendo con ello tanto a la expansión de condiciones de trabajo desiguales entre hombres y mujeres así como a una feminización de las condiciones de trabajo precarias. . Por tanto, la incorporación femenina de género se da todavía en condiciones de desigualdad e inequidad en el marco del capitalismo flexible, a pesar del discurso imaginario hegemónico de igualdad de oportunidades. f. en síntesis el patrón de tipo patriarcal sigue produciéndose y reproduciéndose como un elemento organizador en la inserción laboral. g. En estas condiciones las políticas públicas recomiendan transversalización e institucionalización de una perspectiva de género para modificar, por lo menos en parte, las relaciones de desigualdad observables en los diferentes sectores de la economía y de la sociedad.

\section{Algunos aspectos metodológicos}

La investigación básica de la problemática nos llevo a trabajar bajo un diseńo de carácter exploratorio con un enfoque sistémico cuantitativo y cualitativo aplicando entrevistas a profundidad para captar en su multidimensionalidad cualitativa el problema. Aplicamos asi mismo una encuesta virtual a los egresados del periodo 2010-2014 de las especialidades de ingeniería industrial, educación, filosofía, biología, administración y sociología, bajo una muestra dirigida buscando descubrir los procesos, situaciones y expectativas con relación a la insersión laboral como sus perspectivas y limitaciones en el propio campo específico del mercado laboral.

La encuesta virtual elaboró un cuestionario sobre la base de la tecnología google docs que ofrece el diseño y el monitoreo de los formularios junto a un Excel virtual. Al mismo tiempo las bases de datos las organizamos dentro de carpetas en el google drive lo que permitió el seguimiento del acopio de información cuantitativa. Mientras la encuesta virtual nos permite presentar algunas tendencias cuantitativas, la guía de entrevista nos permitirá en un estudio posterior precisar mejor las situaciones y problemáticas de la inserción laboral de los profesionales sanmarquinos. El cuadro de variables e indicadores para el análisis quedó planteado en los siguientes términos:

\section{INCORPORACIÓN LABORAL}

- Año de ingreso

- Grado académico actual

- Especialidad profesional

- Medio de acceso al primer trabajo

- Requisitos para acceder al primer trabajo

- Tiempo para acceder al primer trabajo

- Dificultad de acceso al primer trabajo

- Grado de dificultad de acceso al primer trabajo

- Utilidad de prácticas preprofesionales

- Calificación de la formación profesional

- Influencia del prestigio de la universidad

\section{SITUACIÓN LABORAL}

- Número de trabajos hasta la fecha

- Condición laboral actual

- Ejercicio profesional activo

- Lugar de principal trabajo actual

- Dificultad de acceso de principal trabajo actual

- Grado de dificultad de acceso a principal trabajo actual

- Tiempo dedicado a principal trabajo actual

- Frecuencia de principal trabajo actual

- Requisitos de acceso a principal trabajo actual

- Puesto de trabajo principal actual

- Medios de acceso a puesto de principal trabajo actual

- Funciones laborales actuales

- Dificultad en realizar principal trabajo actual

- Posibilidades de ascenso laboral

- Ingreso económico mensual

- Trabajo adicional

\section{SATISFACCIÓN Y EXPECTATIVAS LABORALES}

- Nivel de satisfacción de principal trabajo actual

- Desempeño laboral respecto a formación profesional

- Calificación de mercado laboral

- Expectativa laboral 
- Expectativa profesional

- Factores condicionantes de ingreso económico

- Autoempleo como alternativa

- Éxito de acceso a trabajo

\section{Algunos aspectos sociohistóricos}

Manuel Vicente Villarán fue en el siglo XX uno de los primeros científicos sociales que ubico las profesiones como producto del desarrollo económico social capitalista. En 1900, en su discurso, "Las profesionales liberales en el Perú», hace un análisis de la educación peruana y de la realidad del país y con ello de la psicología del hombre peruano. Pensaba que el Perú por su trayectoria económico-social debería ser tierra de labradores, colonos, mineros, comerciantes y hombres de trabajo; pero por la fatalidad de la historia y la voluntad de los hombres ha resultado convirtiéndose en el país donde predominan los intelectuales, literatos, poetas, burócratas, en el que faltan hombres dedicados a la industria con fuerza y espíritu de lucha para obrar en cualquier campo y contribuir al engrandecimiento y progreso del país (UNE-EGYV, 2011).

Por su parte en su tesis para optar el grado de doctor en ciencias políticas: La educación nacional y la influencia extranjera, señalaba:

La educación nacional debe ser democrática. Ni ha de concretarse en un grupo de privilegiados, so pretexto de formar la clase directora; ni ha de consagrarse sólo a las capas sociales inferiores, perdiendo de vista a las elevadas. Ante la exigüidad de nuestra población, conviene suplir el número con la intensa energía de cada unidad, de suerte que la educación universal, equitativamente repartida, conduzca al rendimiento máximo de labor económica, política y social de la diminuta nacionalidad. Para que sea democrática, la educación necesita ser electiva, múltiple, diversificada. La verdadera igualdad de los derechos educativos no ha de consistir en proporcionar a todos la misma especie de instrucción, sino en dar facilidades para obtener educaciones de distintas especies, calidades y grados, según las posibilidades personales. Como hay escuelas de abogados y médicos, de ingenieros y militares, ha de haberlas de comerciantes y mineros, de agricultores y mecánicos. Sólo enseñando todo, puede el Estado democrático enseñar a todos para que dentro de la multiplicidad de materias y la diversidad de escuelas, se ejercite ampliamente la adaptación electiva de los ciudadanos, conforme a sus vocaciones y recursos.
La reforma universitaria de 1919 buscó el encuentro entre formación profesional y realidad del país, situación que social y políticamente no se afrontó hasta 1969 , en la que el gobierno militar y su proyecto político trató de vincular la formación profesional con el modelo propuesto. Las reformas neoliberales de los ańos 90 trastocaron toda la dinámica anterior por la apertura al mercado global y la creciente privatización de las profesiones.

\section{Las escuelas profesionales: hacia un conocimiento histórico}

La profesionalización va unida a nuestra modernización dependiente. Como destaca Oswaldo Salaverry el 9 de septiembre de 1856, en el marco de la reforma educativa emprendida por el gobierno del Mariscal Castilla y a partir del hasta entonces vigente Colegio de la Independencia, se crea la Facultad de Medicina de San Fernando, reintegrando la enseńanza de la medicina al seno de la Universidad de San Marcos y culminando un proceso que se había iniciado más de sesenta años antes, en el periodo virreinal, y que sentó las bases para la enseñanza moderna de las ciencias médicas en el Perú. Desde entonces han transcurrido más de150 años de fructífera labor del alma máter de la medicina peruana y su efemérides es una buena oportunidad para recordar sucintamente la génesis y el sentido de la fundación de la primera Facultad de Medicina del Perú.

La opinión favorable de Ulloa, sobre la medicina como institución en 1856, se basa en lo que considera como las funciones de sus practicantes; según su entender el médico cumple una triple función: "custodios de la salud pública, auxiliares de la justicia para el descubrimiento de los crímenes y de confidentes y agentes de beneficencia en el hogar doméstico". Eso bastaría para que la medicina se eleve por encima de otras profesiones y se convierta en una institución (Salaverry, 2006).

La Universidad Nacional de Ingeniería (UNI) fue fundada el 18 de marzo de 1876 por iniciativa del Estado de la República del Perú. Inicialmente fue creada como Escuela de Ingenieros del Perú. Destaca en ciencias, ingenierías, tecnologías y artes aplicadas.La UNI está organizada en 11 facultades que abarcan 28 especialidades. Nace debido a la creciente industrialización del país y por la necesidad de contar con profesionales peruanos que puedan desarrollar grandes obras como la explotación minera, diseño y construcción de líneas 
férreas y carreteras, puentes, etc. En el año de 1910 se implementó una reforma de la entonces Escuela con el objetivo de adaptarse a los nuevos tiempos y las nuevas tecnologías surgidas por esa época. La industrialización sustitutiva y la apertura neoliberal marcan su desarrollo en los últimos setenta años.

En San Marcos, Medicina tuvo una influencia en la creación de nuevas carreras. La UNI influye, asimismo, en la creación de carreras afines. Como destaca en el portal web (http://www.unmsm.edu.pe/home/inicio/ historia) en el siglo XX fueron organizadas cinco nuevas Facultades, cuatro en el área de Ciencias: Farmacia y Bioquímica, Odontología, Medicina Veterinaria, Química y Educación en el área de Humanidades. La de Teología adquirió un régimen distinto en 1935 y dejó de formar parte de San Marcos. En consecuencia, en 1969 solo existían tres Facultades que procedían de la época colonial: Letras y Ciencias Humanas (antes Facultad de Artes), Derecho (Leyes y Cánones) y Medicina.

A partir del siglo XX, con la especialización del conocimiento, muchas carreras se independizaron y motivaron la creación de diversas Facultades, al punto que actualmente la Decana de América cuenta con 62 carreras (correspondientes a cinco áreas académicas) distribuidas en 20 Facultades: Facultad de Letras y Ciencias Humanas, Facultad de Derecho y Ciencia Política, Facultad de Medicina, Facultad de Farmacia y Bioquímica, Facultad de Odontología, Facultad de Educación, Facultad de Química e Ingeniería Química, Facultad de Medicina Veterinaria, Facultad de Ciencias Administrativas, Facultad de Ciencias Biológicas, Facultad de Ciencias Contables, Facultad de Ciencias Económicas, Facultad de Ciencias Físicas, Facultad de Ciencias Matemáticas, Facultad de Ciencias Sociales, Facultad de Ingeniería Geológica, Minera, Metalúrgica y Geográfica, Facultad de Ingeniería Industrial, Facultad de Psicología, Facultad de Ingeniería Electrónica y Eléctrica, Facultad de Ingeniería de Sistemas e Informática.

El origen de una Facultad muchas veces surge de cursos que integraban la currícula de profesiones que con el paso del tiempo han ido diversificando su conocimiento y especializándolo, como ya se dijo, al punto de que empezaron a cobrar por sí propio un peso gravitante que determinó su autonomía, ya sea integrándose en un primer momento en Departamentos Académicos o en Institutos.

La Facultad de Letras y Ciencias Humanas (FLCH) no es sino la continuidad de lo que fuera la Facultad de Teología y de Artes, fundada en 1553. En ese sentido, desde el punto de vista histórico la Facultad de Letras y Ciencias Humanas aparece como la más antigua Facultad de la Universidad de San Marcos y, en consecuencia, de América. Le siguen en antigüedad, las Facultades de Derecho (1571) y de Medicina (1634), primacía cronológica que debe ser oficialmente reconocida y respetada en todos los actos universitarios de San Marcos.

Un ejemplo de cómo la preponderancia social determina la independización de determinados programas o departamentos se da, precisamente, en la FLCH. Así, hasta 1946, la sección pedagógica formaba parte de la Facultad de Letras y Pedagogía, luego se independizaría y se crearía la Facultad de Educación. Asimismo, en 1954 se crea la Sección de Psicología de la FLCH y para 1988 se crea la Facultad de Psicología, que actualmente cuenta con un moderno pabellón separado de la FLCH y ubicado en la Ciudad Universitaria.

Otro tanto se puede decir de la Facultad de Ciencias Sociales, que se crea tomando como base la Dirección de Programas de Ciencias Sociales, perteneciente a Letras. La actual carrera de Antropología, por ejemplo, tiene su antecedente en el Instituto de Etnología de la FLCH. Asimismo, la Facultad de Farmacia y Bioquímica tiene sus orígenes en la creación del Protoboticario en 1808 y la inclusión de la enseńanza de Farmacia en el cuadro sinóptico del plan de estudios del colegio de Medicina, Farmacia y Cirugía. En 1931 se crea la Escuela de Farmacia, que originaría en 1943 la Facultad de Farmacia y Bioquímica.

Otro antecedente interesante es el caso de la Facultad de Ciencias Políticas y Administrativas, creada en 1875 como parte del proceso de modernización del gobierno de Manuel Pardo (1872-1876). El propósito de la creación de la referida Facultad era la formación de funcionarios para la administración pública y la diplomacia. Sin embargo, en 1928, la Facultad de Ciencias Económicas reemplazó a la anterior Facultad de Ciencias Políticas y Administrativas. En 1980, se produce la separación de los Programas y Departamentos de Contabilidad y Administración y en 1984 se crea la actual Facultad de Ciencias Administrativas.

A la Facultad de Ciencias Económicas pertenecía el Instituto Superior de Ciencias Contables, creado en 1936, en donde se formaron los primeros contadores públicos de Lima. Luego de varias reformas curriculares y reestructuraciones de las áreas de estudio, en 1984 se crea la Facultad de Ciencias Contables. En cuanto a 
las ingenierías y ciencias básicas, en 1983 se aprueba la creación de las 17 Facultades que dieron origen a una nueva etapa histórica en San Marcos, de donde nacería la Facultad de Geología, Minas, Metalúrgica, Ciencias Geográficas y Mecánica de Fluidos.

En 1991, a pedido del Consejo de Facultad, la Asamblea Universitaria reestructura la conformación de la Facultad y la Escuela Académico Profesional de Mecánica de Fluidos pasa a integrar a la Facultad de Ciencias Físicas. En el año 1995, la Escuela de Geología se fusiona con la de Ingeniería Geológica y la de Ciencias Geográficas, y es a partir de entonces que la nueva denominación es Facultad de Ingeniería Geológica, Minera, Metalúrgica y Geográfica.

Una facultad que ha mantenido su preeminencia académica y autonomía sin muchos sobresaltos es la de Ciencias Matemáticas, la cual inicia su funcionamiento en el año 1850. En 1862 se le denominó Facultad de Ciencias Naturales y Matemáticas, posteriormente en 1876 toma el nombre de Facultad de Ciencias. Hoy en día se le denomina Facultad de Ciencias Matemáticas.

Otra carrera que con el paso del tiempo adquirió tal grado de especialización que hubo de independizarse fue Ingeniería Industrial: al promulgarse el Estatuto de la Universidad, en setiembre de 1984, el Programa Académico de Ingeniería Industrial se convierte en la Escuela Académico Profesional de Ingeniería Industrial integrando la Facultad de Ingeniería Industrial e Ingeniería Electrónica. Para diciembre de 1988, la Asamblea Universitaria considera conveniente darle autonomía creándose de esta manera la Facultad de Ingeniería Industrial.

Cabe también resaltar a la que fuera, en el siglo XIX, la Facultad de Matemáticas y Ciencias Naturales, cuyo plan de estudios incluía, entre otras materias de enseñanza, a la cátedra de Historia Natural, que tuvo como primer docente nada menos que a Antonio Raimondi Dell'Acqua quien fuera también el primer decano de la Facultad de Ciencias.

Andando el tiempo, hubo una notable reforma en los Programas de Estudio de Ciencias Biológicas, cuyos biólogos egresaban de la Facultad de Ciencias. La Escuela Instituto de Ciencias Biológicas tuvo vigencia hasta octubre de 1968, año en que se instituyeron en la universidad los Programas Académicos y Departamentos Académicos. Por fin, en 1984 se crea la Facultad de Ciencias Biológicas.

En el caso específico de la sociología en la Universidad Nacional de San Marcos podemos observar también esta dinámica de desarrollo profesiones, mercado, estado y sociedad. En un estudio reciente hemos señalado las siguientes etapas (Ríos, Romero, Huaytalla, 2015)

Un caso típico de antecedente: la sociología. Regresando al origen (1961-1968)

La sociología se institucionaliza en el año 1961, con la creación del Departamento de Sociología, en la Universidad Nacional Mayor de San Marcos y en la Universidad Nacional del Centro del Perú; en la Universidad San Agustín de Arequipa en 1963, en la Pontificia Universidad Católica del Perú en 1964 y en la Universidad Nacional Federico Villarreal en 1968. Una década de apertura y expectativa para una nueva carrera profesional: la sociología. El nacimiento institucional de la sociología estuvo aparejado, desde su inicio, con dos propuestas en disputa. La primera, el origen de su fundación institucional, una sociología que sea llamada a solucionar problemas sociales específicos de la sociedad, entre ellos la irrupción de los movimientos sociales críticos a regímenes oligárquicos a la par que de procesos como la industrialización, la urbanización, oleadas migratorias, que empiezan a desbordar y cambiar el rostro del Perú. Para lograr tal proyecto, organizaciones externas fueron de importancia.

\section{Técnicos públicos del gobierno militar (1968-1975)}

El ascenso al gobierno "revolucionario" de las Fuerzas Armadas bajo la dirección del general Juan Velasco Alvarado trajo consigo un crecimiento del Estado peruano. Las necesidades del gobierno acarrearon una brusca ampliación de los aparatos estatales y con ellos la demanda de profesionales, entre estos, profesionales en sociología. El resultado fue la ampliación del mercado ocupacional de la sociología, la creación de Escuelas de sociología, y como consecuencia, el incremento de estudiantes y profesores. Así pues, Degregori y otros sostendrán que la dictadura militar significó para las ciencias sociales en el Perú una etapa de "crecimiento y consolidación” (Degregori et. al., 2001: 19).

\section{Técnicos en las ONG: ¿Y la política? (1975-1990)}

Es recién a fines del setenta que las Organizaciones no gubernamentales de desarrollo (en adelante ONG) encuentran terreno fértil para brotar masivamente. Contexto que guarda cercanía con la salida de los pro- 
fesionales en sociología del Estado, lo que permitió su actuación en estas instituciones. Para Lynch las ONG serán un "espacio de refugio".

"Viejas" criticas y "nuevas" funciones (1991-2014)

Esta etapa presenta dos momentos. El primero, dedicada a la década del noventa, la preparación de terreno para construir una sociología profesionalizante con nuevas pautas, alejándose parcialmente de las "viejas críticas" y mostrándose con nuevos técnicos apartados de ideales revolucionarios. El segundo, que empieza desde inicios del siglo XXI hasta la actualidad, que se caracteriza por un tímido y difuso acceso de la sociología a los nuevos mercados laborales.

Desafíos frente a la consolidación del mercado neoliberal (2000-2014)

Ahora bien, actualmente, en general se observa que los sociólogos (73.7\%) trabajan, principalmente, en el sector público, lo que en el caso de las mujeres es menor, independientemente del sector en el que trabajan, tal como se puede evidenciar en el siguiente cuadro. Esta situación no es exclusiva del campo de la sociología, pues en el mundo profesional y laboral, las mujeres van tomando un proceso de creciente emergencia y posicionamiento en el mercado laboral, cuando antes su situación era por demás marginal o subordinada a la predominancia laboral masculina.

\section{La inserción de los profesionales sanmarquinos en el mercado global hoy}

Entre los resultados de la investigación e interpretación de datos podemos destacar, inicialmente, los siguientes: La formación y distribución por sexo en las carreras podemos observarlo en el gráfico 1:

GRÁFIC0 1

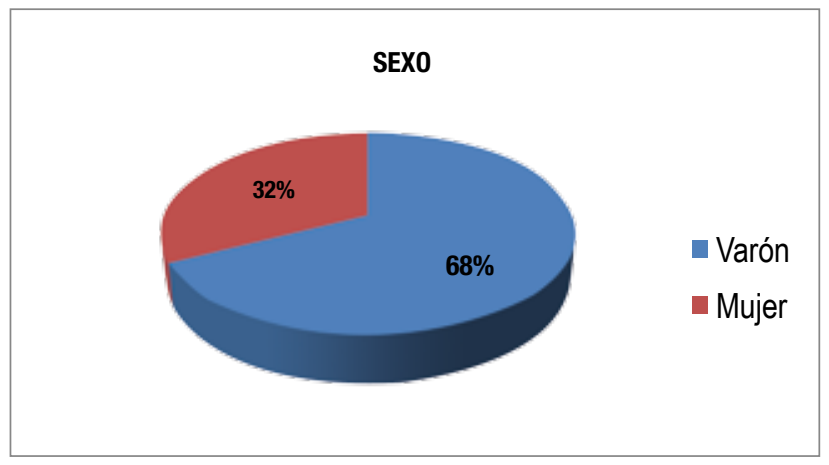

Fuente: Elaboración a partir de la encuesta aplicada.

GRÁFICO 2

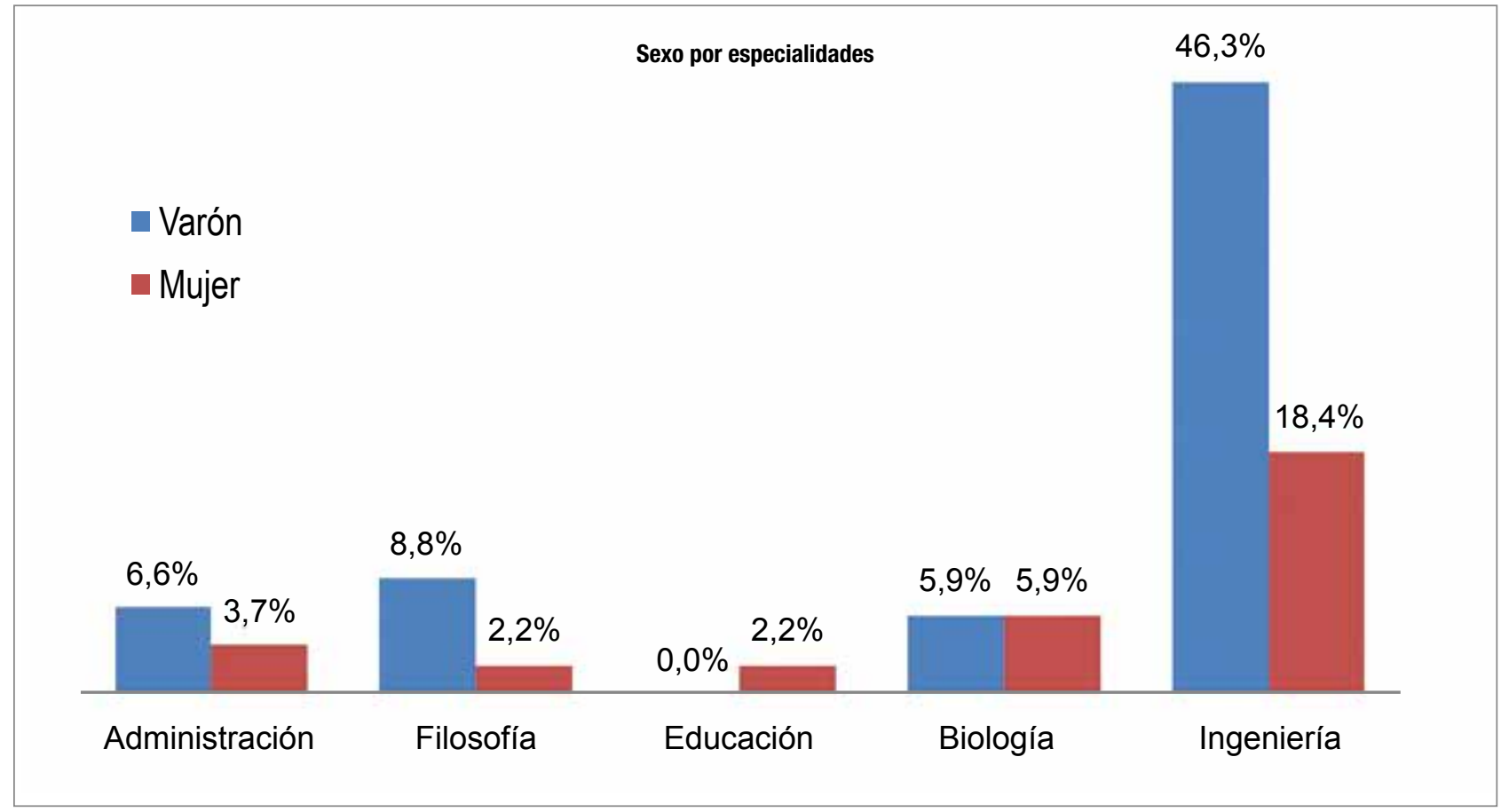

Fuente: Elaboración a partir de la encuesta aplicada 
Según los resultados de la encuesta, se puede apreciar que el mayor número de entrevistados corresponde al sexo masculino, con un $68 \%$, mientras que el sexo femenino alcanza un 32\%. Cabe indicar también que cada vez más resalta la presencia femenina en las carreras y su inserción en el mercado laboral. El gráfico 2 nos ubica en su distribución por especialidades.

Puede apreciarse que el mayor número de personas del sexo masculino se ubican, todavía, en carreras vinculas a las ingenierías y otras consideradas "masculinizadas", pero resalta la presencia masculina en carreras como filosofía y administración. Aquí también una información general nos hace ver la cada vez mayor presencia femenina en cada una de las carreras analizadas, como nos muestra el caso de educación, en donde generalmente predominan.

El gráfico 3 nos lleva al conocimiento de la obtención del grado de bachiller:

GRÁFICO 3

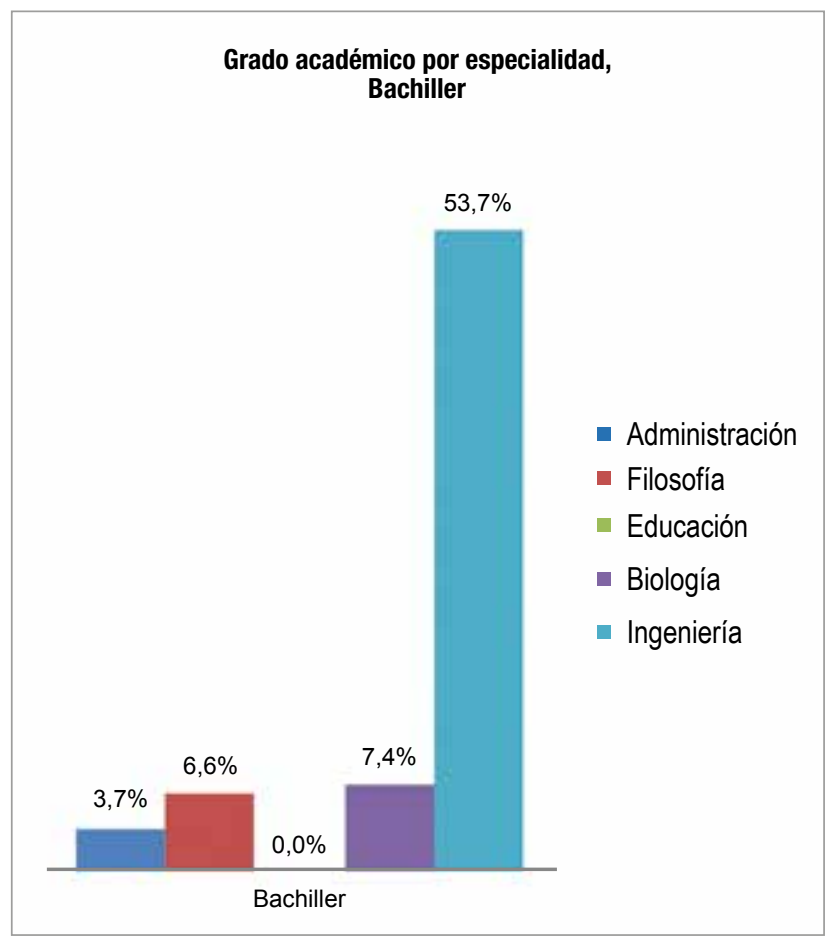

Fuente: Elaboración a partir de la encuesta aplicada.

Con respecto al grado académico por especialidad destacamos que cada vez más el mercado laboral exige la especialización con los grados respectivos, ello se aprecia en la muestra de egresados del período 2010 al 2014. Así puede notarse en el gráfico 3, como ejemplo el caso de administración, donde más del $50 \%$ de entrevistados posee el grado de bachillerato.

El gráfico 4 a la obtención del grado de licenciatura:

GRÁFICO 4

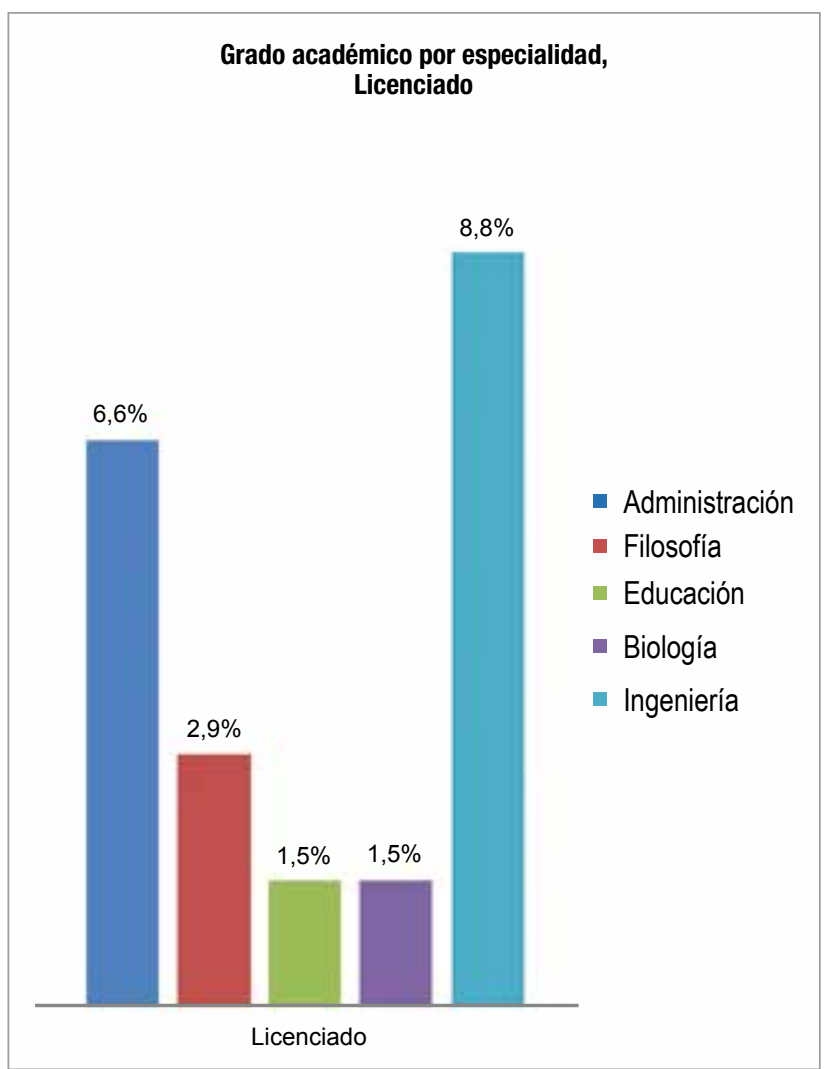

Fuente: Elaboración a partir de la encuesta aplicada.

Profundizando la descripción anterior, notamos que el grado académico por especialidad tiene a estancarse y en algunos caso a disminuir a diferencia de lo que vienen ocurriendo en algunas universidades privadas donde la tendencia es a aumentar progresivamente a través de las facilidades institucionales. Los factores que explican esta situación muestran la crisis de la universidad pública con respeto a la titulación de sus egresados.

Por ejemplo, si bien en administración el gráfico 4 nos muestra un mayor porcentaje de licenciados y licenciadas, es todavía un número mucho menor al otro grupo de egresados que no han logrado todavía su titulación, ante ello cabe preguntarse ¿Cuáles son causas de que los ex estudiantes no obtengan su licenciatura? El gráfico 5 nos muestra la situación de la maestría: 
GRÁFICO 5

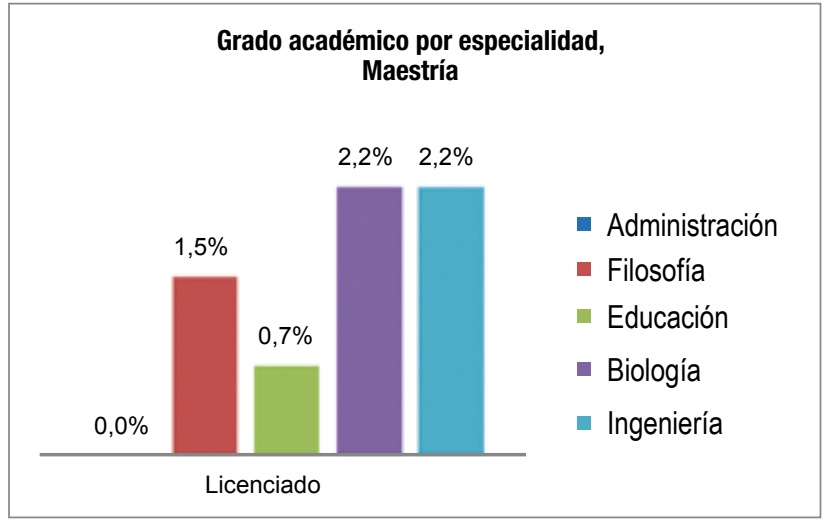

Fuente: Elaboración a partir de la encuesta aplicada

En el caso de la maestría la situación se evidencia con mayores dificultades para la obtención del desarrollo profesional en cuanto al grado académico. Si observamos con atención el gráfico 5 notamos que, en general, el promedio de maestristas es muy bajo aun considerando una muestra inicial que incluye a egresados de la universidad hace cinco años, es decir, egresados del año 2010 que no inician su maestría. Ante ello, cabe preguntarnos, a qué se debe qué un grupo muy reducido de los egresados realicen su maestría.

El gráfico 6 nos presenta la situación del doctorado:

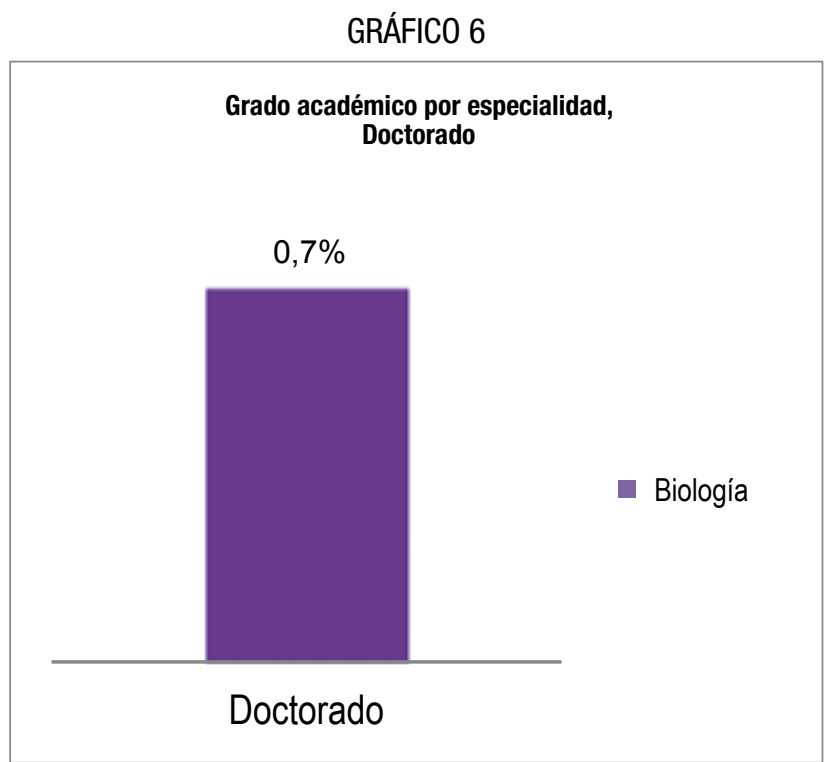

Fuente: Elaboración a partir de la encuesta aplicada.

La evidencia más saltante de esta situación es el caso del doctorado donde notamos la bajísima presencia de doctores, con excepción de la especialidad de biología.
El gráfico 7 la situación del grado por especialidad: GRÁFICO 7

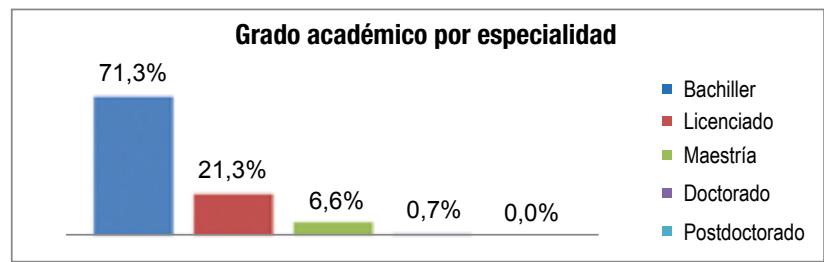

Fuente: Elaboración a partir de la encuesta aplicada

En resumen, podemos observar en el gráfico 7 que si bien los bachilleres con relación a los licenciados alcanzan una mayor proporción, la tendencia tiende a disminuir en cuanto el grado de maestría y doctorado, como se ha mostrado en los gráficos anteriores.

El gráfico 8 nos hace ver inicialmente la situación de la dificultad laboral:

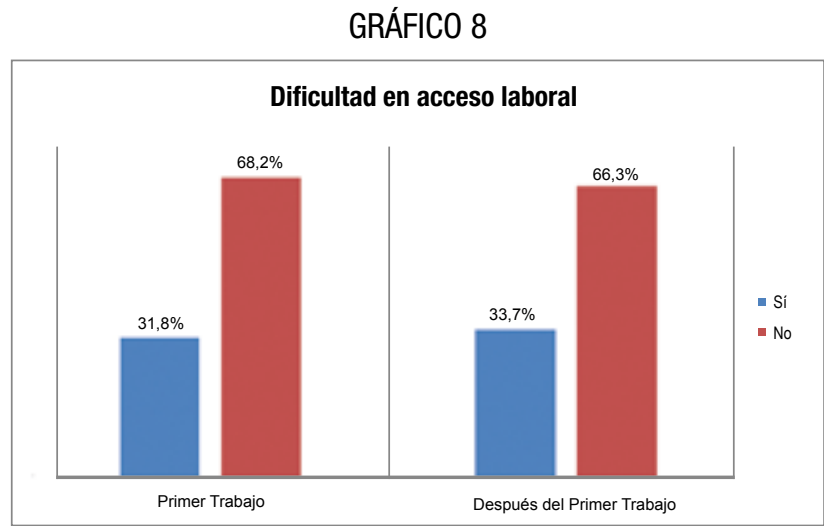

Fuente: Elaboración a partir de la encuesta aplicada.

Con relación a la dificultad en el acceso laboral se destaca que a mayor cantidad de trabajos en la trayectoria laboral del egresado las dificultades persisten, pero posiblemente tienen otras dificultades específicas. Mientras que los que tienen un trabajo manifiestan que la dificultad mayor es la escasa experiencia laboral (82.1\%), los que tienen más cantidad de trabajos en su trayectoria sostienen que sus dificultades son las pocas redes de contactos (50\%), como puede observarse en el gráfico 9 . 
GRÁFICO 9

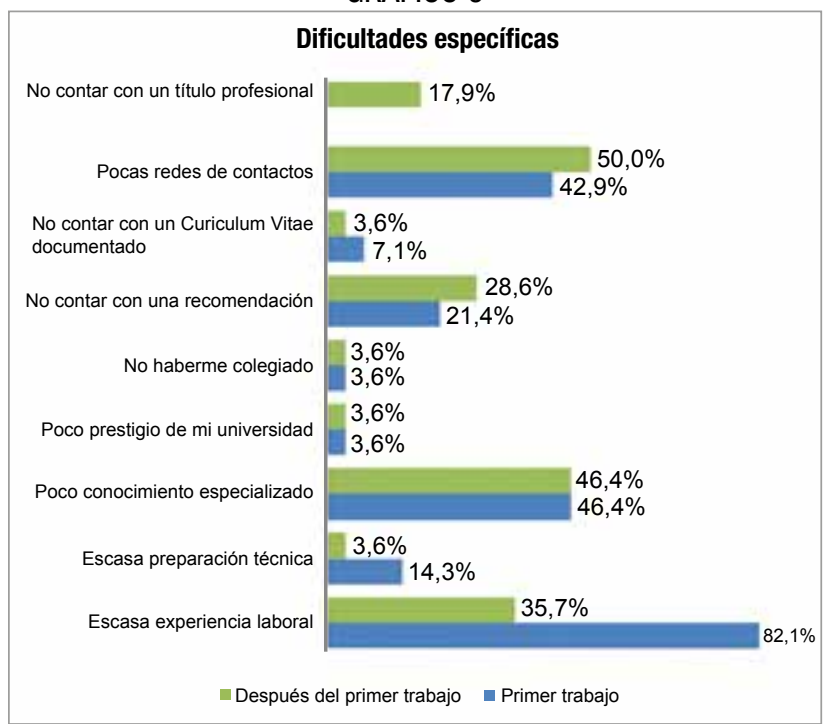

Fuente: Elaboración a partir de la encuesta aplicada

Ahora bien, en el gráfico 10, los grados de dificultad en el acceso laboral, ya sea en los que tienen un primer trabajo y los que tienen más de uno, manifiestan que tienen regular dificultad.

\section{GRÁFICO 10}

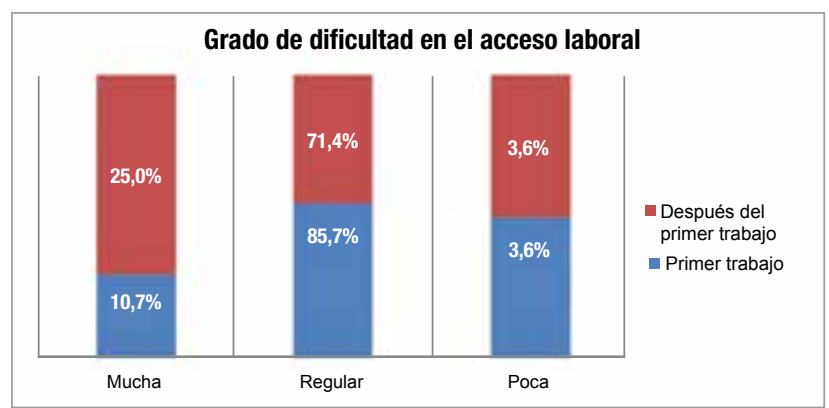

Fuente: Elaboración a partir de la encuesta aplicada

A continuación presentamos los requisitos principales de acceso laboral, según las especialidades analizadas. En general notamos que los requisitos más destacados son dos: habilidades y competencias técnicas y el título profesional. Así, mientras los egresados con mayor experiencia laboral en la especialidad de administración resaltan las habilidades y competencias (8.1\%), la especialidad de filosofía resalta el título profesional $(6.6 \%)$.
GRÁFICO 11

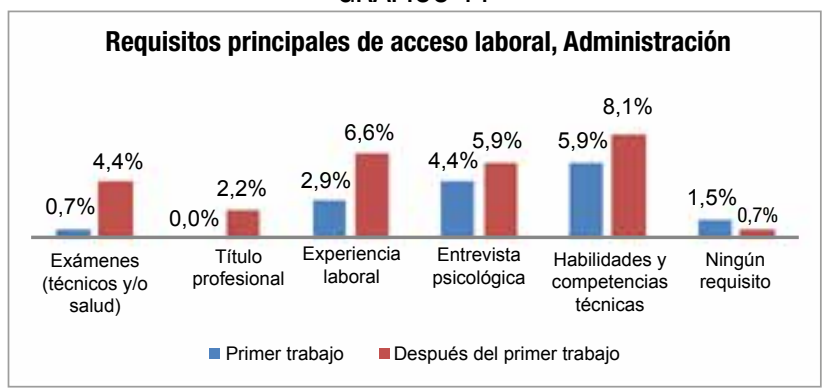

Fuente: Elaboración a partir de la encuesta aplicada

GRÁFICO 12

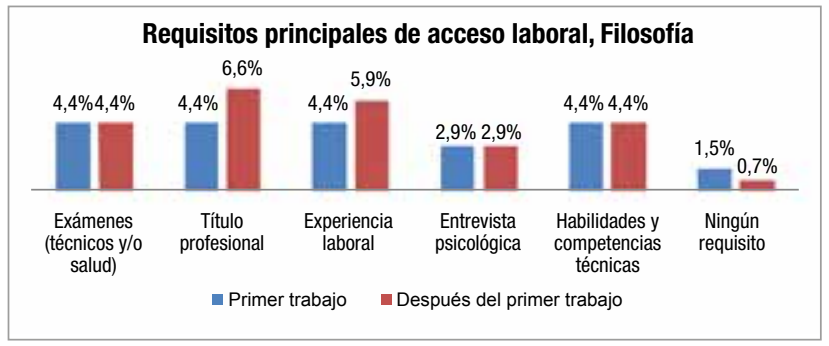

Fuente: Elaboración a partir de la encuesta aplicada

GRÁFICO 13

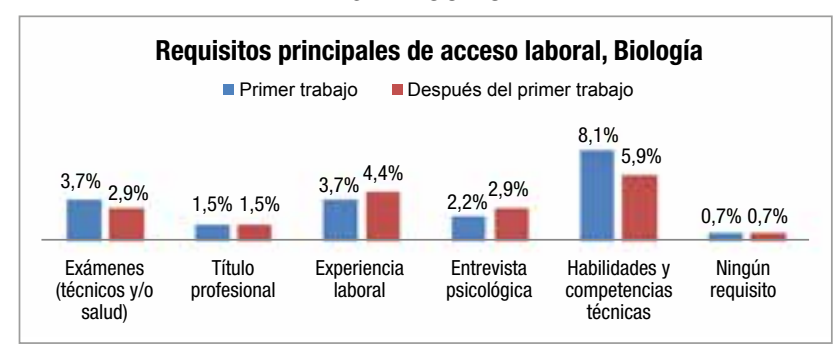

Fuente: Elaboración a partir de la encuesta aplicada

GRÁFICO 14

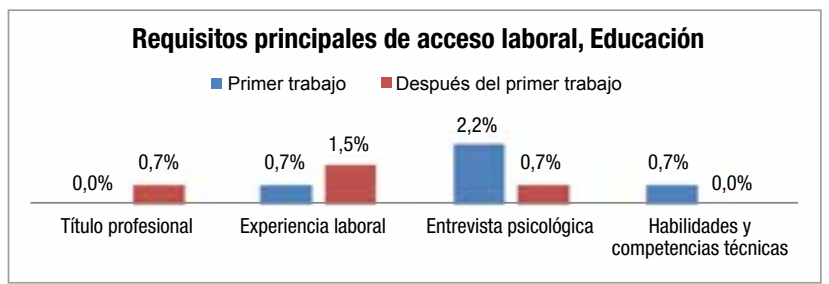

Fuente: Elaboración a partir de la encuesta aplicada

\section{GRÁFICO 15}

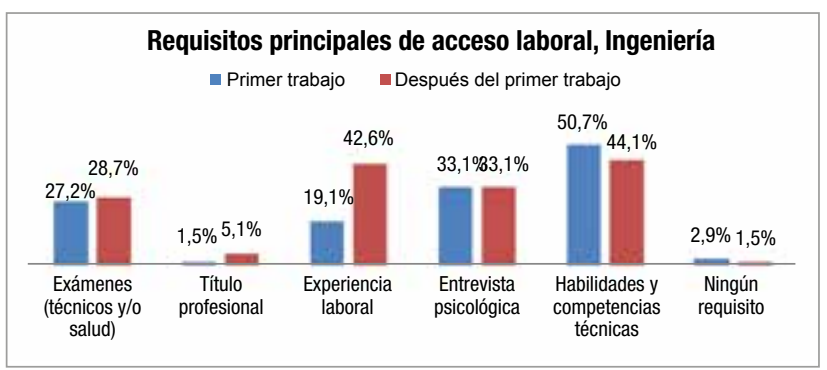

Fuente: Elaboración a partir de la encuesta aplicada 
Otro de los aspectos analizados se relaciona con la demora en el acceso al trabajo, variable que la hemos medido en meses. Podemos notar al respecto que los egresados con mayores posibilidades de acceso en el corto plazo pertenecen a la especialidad de biología, educación y filosofía.

\section{GRÁFICO 16}

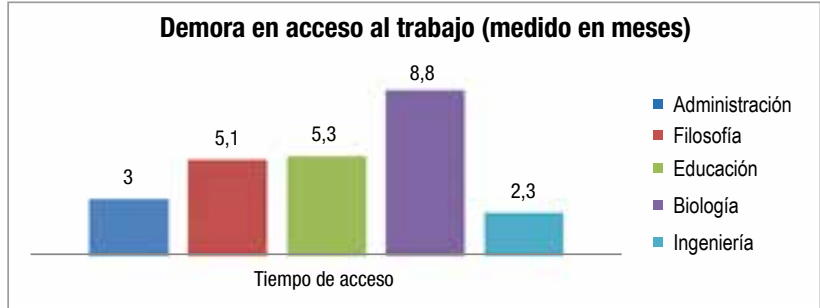

Fuente: Elaboración a partir de la encuesta aplicada

Por otra parte, en la información recogida se destaca la importancia de la utilidad de las prácticas preprofesionales por especialidad, por ejemplo, notamos que en general todas las especialidades resaltan su importancia para el acceso laboral, destacando las carreras de biología e ingeniería industrial.

\section{GRÁFICO 17}

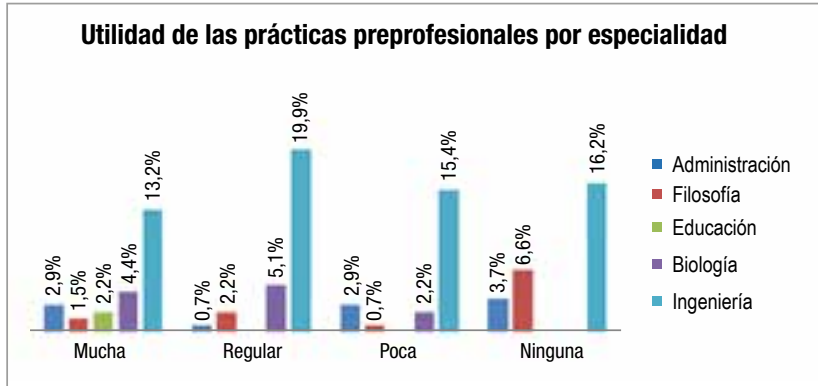

Fuente: Elaboración a partir de la encuesta aplicada

La variable prestigio cumple un papel importante, en tanto la institución reúna las condiciones institucionales de formación y de prácticas preprofesionales vinculadas estrechamente a las exigencias del mercado laboral. En el gráfico 18 notamos:
GRÁFICO 18

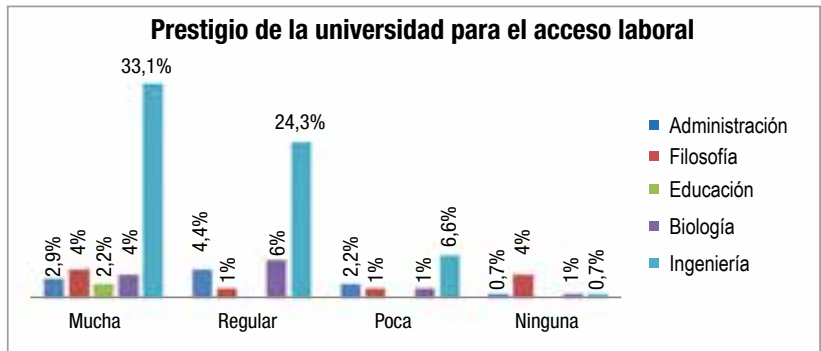

Fuente: Elaboración a partir de la encuesta aplicada

Con respecto al número de trabajos obtenidos hasta la actualidad destaca que en el conjunto de las especialidades han tenido entre 3 a 5 trabajos, de una muestra que corresponde a los egresados del período 2010-2014.

GRÁFICO 19

Número de trabajos hasta la fecha actual por especialidad

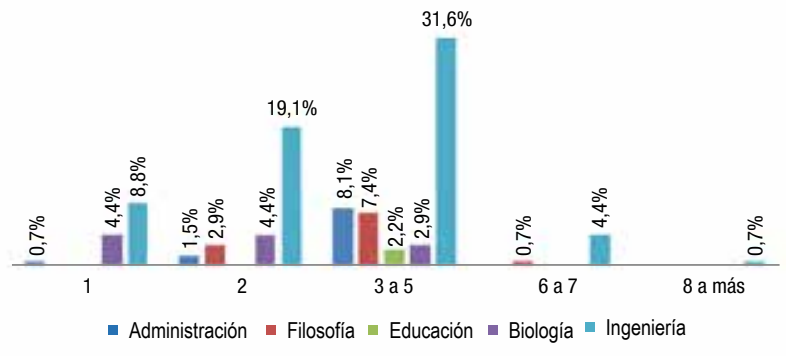

Fuente: Elaboración a partir de la encuesta aplicada

La ubicación laboral de los egresados se da principalmente en el sector privado seguido del sector público. Esta situación nos muestra la creciente relación entre el modelo de crecimiento y desarrollo económico, la flexibilización laboral y privatización de los recursos humanos profesionales en el mercado privado.

GRÁFICO 20

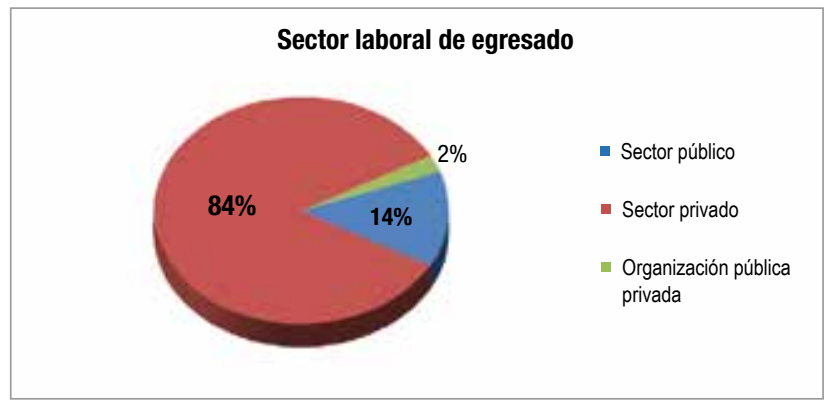

Fuente: Elaboración a partir de la encuesta aplicada. 
En la situación laboral por especialidad resalta principalmente la incorporación de las carreras de ingeniería, administración y biología en el creciente sector privado en globalización. Hecho que no niega la incorporación de las otras carreras, pero dentro de la dinámica aplicada de las necesidades del mercado.

GRÁFICO 21

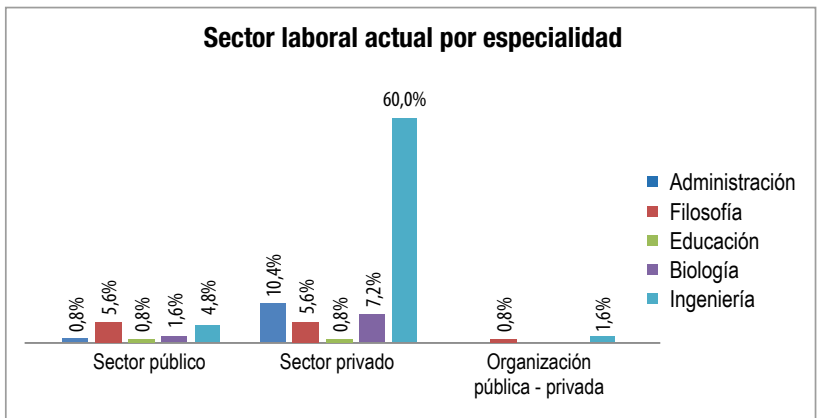

Fuente: Elaboración a partir de la encuesta aplicada.

Con relación al ingreso económico mensual por especialidad resalta el promedio de ingreso de 2001 a 3000 soles, destacando las carreras de ingeniería industrial y administración.

En el gráfico 23 se presenta los rasgos predominantes (meritocrático, estable, amplio, definido y bien remunerado) sobre el mercado laboral, según niveles
GRÁFICO 22

Ingreso económico mensual por especialidad

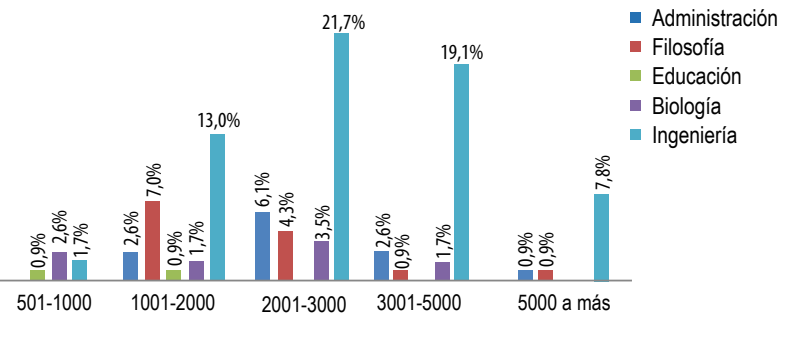

Fuente: Elaboración a partir de la encuesta aplicada.

de calificación: muy de acuerdo, de acuerdo, ni de acuerdo ni en desacuerdo, en desacuerdo y muy en desacuerdo. Con respecto a las percepciones laborales podemos destacar que los egresados de la especialidad de ingeniería industrial manifiestan que su mercado laboral es meritocrático, estable y amplio, en contraste los egresados de filosofía ven a su mercado laboral como definido y los de biología estable y amplio.

El escenario del mercado laboral cada vez más se ajusta a una competitividad individualizada global en el que no solo los egresados orientan y definen su posicionamiento sino se destaca principalmente el rol institucional y de los actores concretos en la construcción y ubicación en el mercado laboral global.

GRÁFICO 23

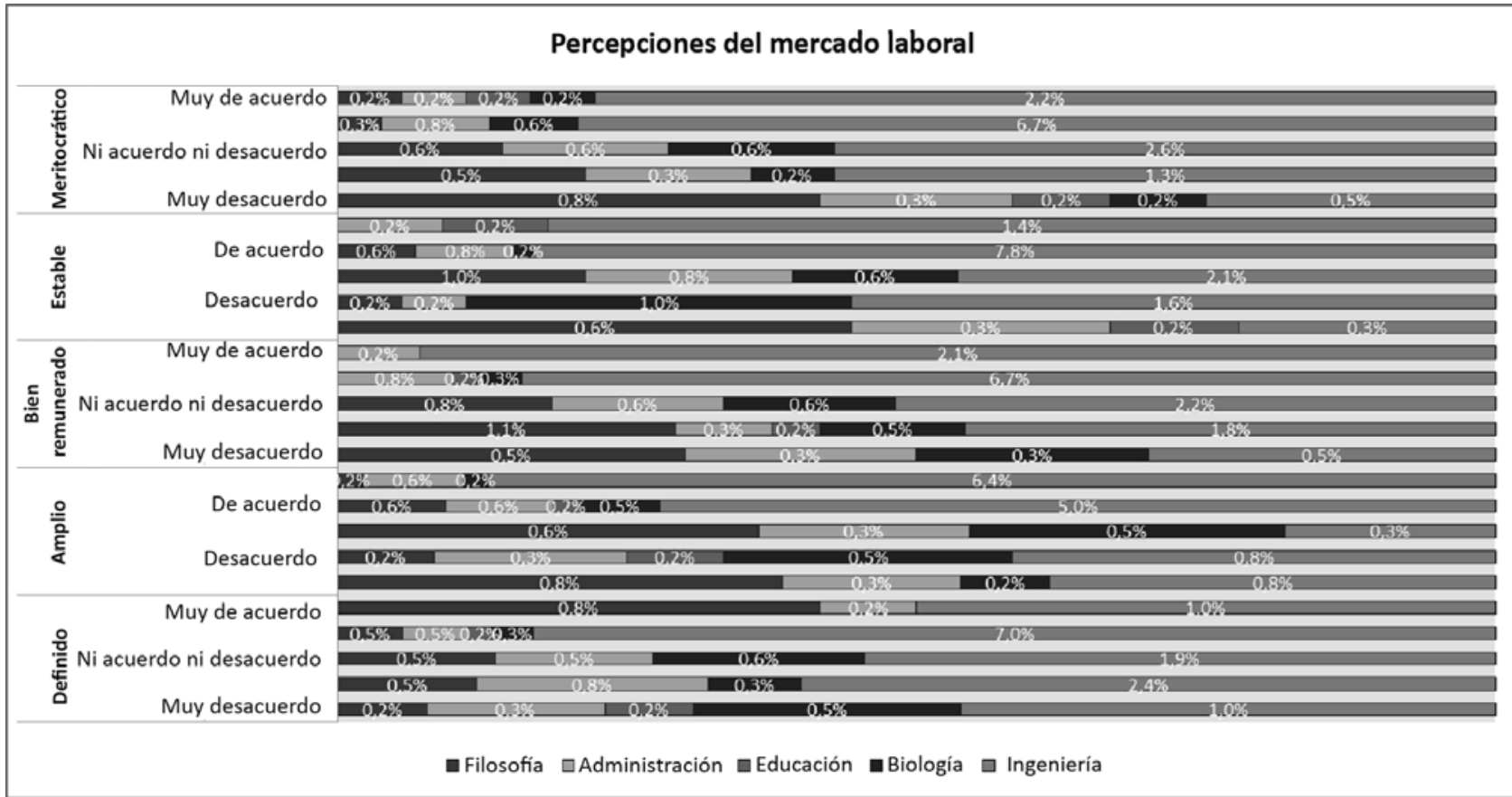

Fuente: Elaboración a partir de la encuesta aplicada. 


\section{Reflexiones finales}

Podemos destacar bajo la forma de conclusiones lo siguiente:

1. Se hace fundamental y necesario desarrollar investigación sistemática sobre la problemática con incidencia para construir una política sistémica de posicionamiento de los profesionales sanmarquinos.

2. La investigación nos muestra que es fundamental construir diseños metodológicos desde la perspectiva empírica dado que se carece de información relevante para su investigación.

3. En el sentido temático resalta que San Marcos a diferencia de otras universidades de prestigio carecen de una política sistémica institucional de posicionamiento de nuestros profesionales en el mercado laboral en globalización.

4. San Marcos se incorpora al mercado laboral de manera diferenciada desde la propia experiencia de los egresados más que de una política proactiva de inserción laboral.

5. La hipótesis de trabajo de investigación se ve confirmada por los datos obtenidos, pues estos muestran que los egresados en términos de género, posicionamiento y expectativas muestran una incorporación diferenciada en el mercado laboral.

6. La tendencia estructural que marca hoy la incorporación en el mercado laboral está dada por su creciente flexibilización y privatización.

7. Pero la investigación evidencia también las crecientes demandas sociales de incorporación de los profesionales a sus diferentes áreas de necesidades e intereses.

8. Las instituciones que no toman en cuenta y definen políticas sistémicas de creación e incorporación al mercado laboral se presentan en una desventaja estructural a las entidades que la construyen.

Asimismo, recomendamos acorde con la investigación que:

1. Durante la investigación se tuvo problemas logísticos respecto a coordinar con las Facultades para que nos puedan proveer los correos personales vigentes de los egresados, con el fin de enviarles las encuestas virtuales. Lo que nos proporcionó el SUM era información pasada. Por eso solicitamos que el vicerrectorado de investigación y posgrado en coordinación con otras instancias institucionales recomienden intensificar el acopio de información sobre la problemática de manera sistemática.
2. Que la universidad consolide un observatorio sobre la problemática de incorporación de nuestros profesionales en el mercado laboral con el fin de lograr un mejor posicionamiento en el mercado global y aplicar políticas universitarias de manera sistémica.

3. En el camino se ha observado que es apremiante que el egresado cuente con un debido seguimiento y estudio, en el sentido que haya más investigaciones no solo desde la misma oficina central de estadística, sino que también se promueva y estimule a las mismas facultades a promoverlas, en el aseguramiento de sus profesionales en el mercado ocupacional.

4. También creemos que es importante el fomento de una cultura organizacional de intercambio de datos sobre el tema entre las escuelas de cada una de las facultades y entre las facultades de la universidad. Esto debido a que nos ha dificultado en la propia investigación, en la etapa de coordinación logística y acopio de información.

5. Desarrollar investigaciones e intercambios con otras experiencia nacionales del mundo.

6. Finalmente, se sugiere que la universidad establezca un programa de implementación progresivo para incorporarlo en la cultura universitaria con el fin de mejorar la información y las políticas. Por tanto, construir una política de posicionamiento de nuestros egresados en el mercado laboral nacional global.

\section{Referencias bibliográficas}

Aguayo, C. (2006). Las profesiones modernas: Dilemas del conocimiento y del poder. Santiago: Universidad Tecnológica Metropolitana.

Arnold, M., Cadena, H. y Urquiza, A. (2014). La organización de las organizaciones sociales. Aplicaciones desde perspectivas sistémicas. Santiago: RIL Editores.

Ballesteros, A. (2007). Max Weber y la sociología de las profesiones. México: UNP-Max Textos. Véase versión electrónica.

BÉJAR, H. (2011). "La San Marcos que conocí", en: Revista de Sociología, vol. 17, No 21. Lima: UNMSM.

Bialakowsky, A. (2013). Coproducción e intelecto colectivo. Buenos Aires: Editorial Teseo.

Bobadilla, P. y Torres, C. (2002). ¿ ‘.. y si no es tu vocación? Mecanismos de elección profesional y la opción por la 
sociología en estudiantes de la PUCP, en: Debates en sociología No 22. Lima: PUCP.

Bonilla, H. (1992). La enseñanza de la historia en las universidades latinoamericanas. Quito: FLACSO.

Bonfiglio, G. (1989). Formación profesional y experiencia laboral en sociología, reflexiones a propósito de un balance, en: Debates en sociología No15. Lima: PUCP.

Burga, C. y Moreno, M. (2001). ¿Existe subempleo profesional en el Perú urbano? Lima: CIES.

Capel, H. (1989). Historia de la ciencia e historia de las disciplinas cientificas. Objetivos y bifurcaciones de un programa de investigación sobre historia de la geografía. Año XII, $\mathrm{N}^{\circ}$ 84. Barcelona: Geocrítica Cuadernos Críticos de Geografía Humana. Universidad de Barcelona.

Castells, M. (1996). La era de la información. Vol. 1. La sociedad Red. Barcelona: Alianza.

Casanova, P. (2004). Las nuevas ciencias y la humanidades. México: Anthropos-IIS.

CEPAL (2013). La problemática inserción laboral de los y las jóvenes. Santiago: Fondo Editorial CEPAL.

CEPAL (2009). Políticas para la inserción laboral de mujeres y jóvenes en Chile. Santiago: Fondo Editorial CEPAL.

CEPAL (2009). Políticas para la inserción laboral de mujeres y jóvenes en Colombia. Santiago: Fondo Editorial CEPAL.

Cоваs, C. (2010). Graduados y titulados en ciencias sociales periodo 1984-2009. Lima: UNMSM.

Coronel y otros (2005). Sobre las tareas del sociólogo hoy: una mirada desde los alumnos, en: Debates en sociología No 30. Lima: PUCP.

Coordinación de Sociología (2010). Propuesta del perfil del egresado de sociología según estándares de formación. Lima: PUCP.

Coordinación de Licenciatura en Sociología (2009). Seguimiento laboral de egresados 2008. Licenciatura en Sociología de la Facultad de Ciencias Políticas y Sociales de la UAEM, en Espacios Públicos, vol. 12, núm. 26, diciembre.

Dubar, C., Tripier, P. (1998). Sociologie des professions. Paris: Armand Collin Éditeur.

FajnZylber, F. (1992): Industrialización en América Latina. De la <caja negra> al <casillero vacío>. Nueva sociedad 118.rrezuelo, J. La ciencia y la tecnología en la revolución industrial. https://sites.google.com/site/energialbachillerat/Home/la-ciencia-y-la-tecnologia-en-la-revolucion-industrial

Faletto, E. (1996). La Cepal y la sociología del desarrollo. En: Revista de la CEPAL, No 58: Santiago-Chile.

GermanÁ, C. (2011). El campo de la sociología en el Perú, en: Revista de Sociología, vol. 17, No 21. Lima: UNMSM.
GermanÁ, C. (2005), La promesa de la sociología latinoamericana: la ciencia social a construir, en Investigaciones Sociales No 15, Lima: UNMSM.

Germaná, C. (2002). La racionalidad de las ciencias sociales. Lima: UNMSM

GermanÁ, C. (1996). La sociología como ciencia y como profesión, en: Debates en sociología, No 20-21. Lima: PUCP.

Germaná, C. (1993). El discurso de la sociología en el Perú. De las certidumbres de los ańos setenta a las dudas de los años noventa, en: Humberto Rodríguez y Jhony Castillo (Edit.), Investigaciones en ciencias sociales, un balance necesario. Lima: CONCYTEC.

Geyser M. (2009). La demanda del trabajo sociológico y los públicos ¿Qué sociología y para quiénes?, en: El Uruguay desde la sociología. VII reunión anual de investigadores del departamento de sociología. Uruguay: CBA.

Giraldo, R. (1996). Comentarios a la ponencia de César Germaná: la sociología como ciencia y como profesión, en: Debates en sociología No 20-21. Lima: PUCP.

Gonzales, O. (2011). Mariano H. Cornejo y los inicios de la sociología en el Perú, en: Revista de Sociología, vol. 17 No 21. Lima: UNMSM.

GonzÁlez, P. (2004). Las nuevas ciencias y las humanidades. De la Academia a la Política. Madrid: Anthropos-IISEditorial Complutense.

GonzÁlez, P. (2015). Crisis terminal del capitalismo o crisis terminal de la humanidad. México: ALAI AMLATINA.

Gonzales, B. (1996). Cultura y Tercer Mundo 1. Cambios en el saber académico. Venezuela: Nubes y Tierra.

Huaytalla, A. Romero, L. Vargas, Z. (Ed.) (2013). Nosotros los sociólogos. Lima: UNMSM.

Kogan, L. y Galarza, F. (2012). Percepción sobre discriminación en el ámbito académico y laboral de universitarios de cuatro ciudades del Perú. Lima: Universidad del Pacífico.

Latour, B. (1992. Ciencia en acción. Cómo seguir a los científicos e ingenieros a través de la sociedad. Barcelona: Labor.

Latour, B. y Woolgar, S. (1995). La vida en el laboratorio. La construcción de los hechos científicos. Madrid: Alianza.

Levy, A. (2017). ECP. Estrategia, cognición y poder. Cambio y alineamiento conceptual en sistemas sociotécnicos complejos. Buenos Aires: Granica.

LOCKE, J. (1986). On the conducy of human understanding in The Works Basada en Locke, J. (1823).Evans, J. (Ed.) The woks od John Locke. Londres: Scientia Verlag Aalen. Locke, J. Pensamientos sobre educación. Madrid: Akal.

López, S. (2006). Formación de competencias profesionales en egresados de sociología UAM (tesis de maestría). México: FLACSO. 
LóPEZ, S. (1999). Problemas y alternativas en la investigación en sociología, en: Investigaciones Sociales Año III, No4. Lima: UNMSM.

LyNCH, N. (2001). La sociología y el estudio de la política en el Perú, en: Investigaciones Sociales, Año V, No 8. Lima: UNMSM.

LyNCH, N. (2011). Itinerario de la sociología peruana, en: Revista de Sociología, vol. 17 No 21. Lima: UNMSM.

Martins, P. (2012). La decolonialidad de América Latina y la heterotopia de una comunidad de destino solidaria. Buenos Aires: CICCUS-Estudios Sociológicos editora.

Medina, M. (2014). Tecnociencia, en http://ctcs.fff.ub/prometheus/index.htm Editorial Pueblos Unidos.

Mejía, J. (2009). Sociedad y conocimiento. Lima: UNMSM.

MejíA, J. (2009). La sociología en el Perú. Trayectoria histórica y dilemas teóricos, en: Sociedad y conocimiento. Lima: UNMSM.

MejíA, J. (2002). Algunos problemas metodológicos de la sociología en el Perú, en: Problemas metodológicos de las ciencias sociales en el Perú. Lima: UNMSM.

Meneses, M. (2011). 50 años de sociología y sociólogos, en: Revista de Sociología, vol. 17 No 21. Lima: UNMSM.

Molinari, T. (2011). Metateoría, sociología y visiones del Perú, en: Revista de Sociología, vol. 17, No 21. Lima: UNMSM.

Morin, E. (1999). Los siete saberes necesarios a la educación del futuro. París: Organización de las Naciones Unidas para la Educación, la Ciencia y la Cultura. UNESCO. Editorial du Seuil.

Morin, E. (1994). Introducción al pensamiento complejo. Barcelona: Editorial Gedisa.

Montoya, L. (2011). Dilemas e imprecisión temática de la sociología en el Perú, en: Revista de Sociología, vol. 17, No 21. Lima: UNMSM.

NúŃEZ, L. (2013). La escuela académico profesional de sociología de la Universidad de San Marcos (1961-1968), en: Revista de Sociología, vol. 18, No 23. Lima: UNMSM.

OIT (2012). Tendencias mundiales del empleo juvenil 2012. http://www.ilo.org/global/research/global-reports/global-employment-trends/youth/2012/lang--es/index.htm

OCPL (2008). Primera encuesta de inserción laboral de los egresados de la Universidad Nacional Federico Villarreal.

Panaia, M. (2008). Una revisión de la sociología de las profesiones desde la teoría crítica del trabajo en la Argentina. Argentina: CEPAL.

Podestá, B. (1978). Ciencias sociales en el Perú. Un balance crítico. Lima: Centro de Investigación de la Universidad Pacífico.

Portocarrero, G. y Chávez, C. (2001). Enseñanza de socio- logía en el Perú. Lima: CIES y PUCP.

Polanyi, K. (2001). La gran transformación. Bs. As: FCE.

Portocarrero, G. y Chávez, C. (2001). La enseñanza de la sociología en el Perú. Un estudio de casos. Lima: PUCPCIES.

PUCP (2014). Informe sobre el mercado laboral en la especialidad de sociología. Lima: PUCP.

Quijano, A. (1990). Notas sobre los problemas de la investigación social en América Latina, en: Revista de Sociología, vol. 6, No 7. Lima: Facultad de Ciencias Sociales de la UNMSM.

Quijano, A. (1966). Imagen y tareas del sociólogo en la sociedad peruana. Lima: Editorial Jurídica.

Regal, B. (1988). Fundamentos de la ética profesional. Lima: Universidad de Lima.

Reyna, A. у Sото, S. (1996). La sociología Ciencia y profesión en Germaná, en: Debates en sociología No 20-21. Lima: PUCP.

Richter, L. y De Kadt, J. (2010) El desarrollo de las consultorías en Sudáfrica, en: UNESCO. Informe sobre las ciencias sociales en el mundo. México.

Revista Science anuncia los diez logros científicos de 2014 en Tendencias http://www.latercera.com/noticia/ tendencias/2014/12/659-609332-9-revista-scienceanuncia-los-diez-logros-cientificos-de-2014.shtml

Revista Science elige a Rosetta como el avance científico del año enEmol.com - http://www.emol.com/noticias/ tecnologia/2014 /12/18/695264/revista-science-elige-arosetta-como-el-avance-cientifico-del-ano.html

Rifkin, J. (2014). Liderando la tercera revolución industrial. En www.nodo50.org

Ríos, J. Romero, L. Huaytalla, A. (2015). El futuro de la sociología como ciencia social y profesión. Hacia un nuevo paradigma civilizatorio de una ciencia social de vida. Lima: Fondo Editorial UNMSM.

Ríos, J. y Huaytalla, A. (2013). 50 años de sociología en San Marcos. Lima: UNMSM

Ríos, J. (2011) La sociología en el Perú. Entre la colonialidad y la descolonialidad del saber, en: Revista de Sociología, vol. 17, No 21. Lima: UNMSM.

Ríos, J. (2009). Aníbal Quijano: Diálogo sobre la crisis y las ciencias sociales en América Latina 19 Entrevista. Sociológica Revista del Colegio de Sociólogos del Perú. Año I. No 1. Lima: Colegio de Sociólogos del Perú.

Ríos, J. (2001). La sociología en San Marcos. Hacia una revolución teórica del quehacer sociológicos. Lima: JRB.

Rochabrún, G. (1993). La política de la sociología, en: Sociabilidad e individualidad. Materiales para una sociología. Lima: PUCP. 
Rochabrún, G. (1996). La imposible sociología de César Germaná. En: Debates en sociología No 20-21. Lima: PUCP.

Rodríguez, N. (2008). Manual de sociología de las profesiones. Barcelona: Universitat de Barcelona.

Rojas, M. (2015). Sociología de las profesiones. Usos y apropiaciones de las tecnologias de la información y comunicación en la formación del comunicador social, caso: universidad veracruzana.http://www.eumed.net/libros

SARI, H. (2010). Investigación generada por consultorías y ONG en los países árabes del Este: retos derivados. En: UNESCO. Informe sobre las ciencias sociales en el mundo. México.

Santillán, M. (2003). Ética profesional. En: Revista de Facultad de Ciencias Administrativas. Lima: UNMSM.

Salaverry, O. (2006). El inicio de la educación médica moderna en el Perú. La creación de la Facultad de Medicina de San Fernando. Acta Médica Peruana. Vol. 23. № 2. Lima: Colegio Médico del Perú.

Salaverry, O. (2005). Los orígenes del pensamiento médico de Hipólito Unanue. En: Anales de la Facultad de Medicina 66(4). Lima: UNMSM.

Salaverry, O. (2000). Historia de la medicina peruana en el siglo XX. Lima: UNMSM Fondo Editorial.

Soberón, L. (2009). Estudios sobre las competencias de los egresados de sociología de la Facultad de Ciencias Sociales. Informe resultados. Lima: PUCP.

Soria-Silva, S. (2015). Sindicato, profesión y trabajo en el capitalismo. En http://pendientedemigracion.ucm.es/info/ ec/jec10/ ponencias/614soriasilva.pdf

Soria-Silva, S. "Flexibilização, financeirização e liberalização: a santíssima trindade da nova ordem do capital". In: IV Colóquio Latino-Americano de Economistas Politicos: Anais. São Paulo, 2004.

Sulmont, D. (2007). La sociología francesa en el Perú, en: Bulletin de l'Institut Français d'Études Andines No 36. Lima: IFEA.

TANaka, M. (Ed.) (2014). 50 años pensando en el Perú: una reflexión critica.Lima: IEP.
URREA, J. (2012). El origen de las profesiones desde Weber. En https://prezi.com/soojx6t1svsu/el-origen-de-las-profesiones-desde-weber/

VALLE, M. (2011). Las profesiones ante las transformaciones de los mercados de trabajo. México: Universidad Autónoma del Estado de México.

VARGAS, Z. (2011). Sociología y docencia se hace al andar: retos y desafíos. En: Revista de Sociología, vol. 17, No 21. Lima: UNMSM.

VeGA, I. (1996). La construcción social de la sociología. Invitación a la sociología crítica. Lima: Fundación Friedric Ebert.

Villarán, M. (1900). Las profesiones liberales en el Perú. Lima: Imprenta la Industria.

Wallerstein, I. (1976). The modern World System: Capitalist Agriculture and the origins of the European Word Economy in the Sixteenth Century. New York: Academic Press.

Wallerstein, I. (Coordinador). (1996). Abrir las ciencias sociales. México: Siglo XXI Editores.

Weber, M. (1994). La ética protestante y el espiritu del capitalismo. México: Editorial Coyoacán.

Weber, M. (1985). El problema de la irracionalidad en las ciencias sociales. Madrid: Editorial Tecnos.

Weber, M. (1979). El político y el cientifico. Madrid: Alianza Editorial.

Weber, M. (1977). Economía y sociedad: esbozo de sociología comprensiva. 3ra reimp. I y II volúmenes. México: FCE.

Weber, M. (1973). Ensayos sobre metodología sociológica. Buenos Aires: Editorial Amorrortu.

Weber, M. (1967). El político y el cientifico. Madrid: Alianza Editorial.

Weber, M. (1965). Essais sur la Théorie de la Science. Paris: Ed. Librairie Plon.

Weber, M. (1944). Economía y sociedad. Esbozo de sociologia comprensiva. México: Editorial FCE.

Weller, J. (2007). La inserción laboral de los jóvenes: características, tensiones y desafios. Santiago: Revista de la CEPAL, $\mathrm{N}^{\circ}$ 92, agosto. 